\title{
A survey of the relationship between functional genes and acetaldehyde production characteristics in Streptococcus thermophilus by multilocus sequence typing
}

\author{
Wenjun Liu, ${ }^{1,2}$ Xin Su, ${ }^{1,2}$ Nala Duo, ${ }^{1,2}$ Jie Yu, ${ }^{1,2}$ Yuqing Song, ${ }^{1,2}$ Tiansong Sun, ${ }^{1,2}$ Musu Zha, ${ }^{1,2}$ Bilige Menghe, ${ }^{1,2}$ \\ Heping Zhang, ${ }^{1,2}$ and Zhihong Sun ${ }^{1,2 *}$ \\ ${ }^{1}$ Key Laboratory of Dairy Biotechnology and Engineering, Ministry of Education, Inner Mongolia Agricultural University, Hohhot, 010018, China \\ ${ }^{2}$ Key Laboratory of Dairy Products Processing, Ministry of Agriculture and Rural Affairs, Inner Mongolia Agricultural University, Hohhot, 010018 , \\ China
}

\section{ABSTRACT}

Streptococcus thermophilus is an important bacterium used in the production of fermented dairy products. Yogurt with good flavor is preferred by consumers; thus, variation in flavor-formation characteristics among isolates is attracting attention. Here, acetaldehyde production characteristics of 30 isolates were evaluated in parallel with genotyping and multilocus sequence typing of key functional genes involved in acetaldehyde production. The results showed that isolates could be divided into 3 phenotypically distinct groups: high-acetaldehyde-yielding isolates $(>10$ $\mathrm{mg} / \mathrm{L})$, medium-acetaldehyde-yielding isolates (5-10 $\mathrm{mg} / \mathrm{L})$ and low-acetaldehyde-yielding $(<5 \mathrm{mg} / \mathrm{L})$ based on evaluation of acetaldehyde production during yogurt storage. These groups, distinguishable by phenotypic characteristics, were clustered in corresponding groups based on functional gene multilocus sequence typing analysis. Combining functional gene sequence analysis of 30 Strep. thermophilus isolates with phenotypic evaluation of their flavor-related characteristics (specifically acetaldehyde production) demonstrated that groups of isolates established using genotype data analysis corresponded with groups identified based on their phenotypic traits. Interestingly, the 30 isolates of Strep. thermophilus showed significant phylogenetic clustering in acetaldehyde content by functional gene and acetaldehyde content analysis. A corresponding relationship exists between functional gene phylogenetic clustering and acetaldehyde content variation.

Key words: Streptococcus thermophilus, multilocus sequence typing, functional genes, flavor production

Received December 21, 2018.

Accepted July 9, 2019.

*Corresponding author: sunzhihong78@163.com

\section{INTRODUCTION}

Consumption of yogurt, an ancient and nutritious food, is increasing as a result of its beneficial effects on human health (Astrup, 2014; El-Abbadi et al., 2014; Rizzoli, 2014). Biochemically, yogurt is a complex gel comprising proteins, polysaccharides, and lipids. It is a mixture of milk (whole, low fat, or nonfat) and sometimes cream, that has been fermented by the lactic acid bacteria (LAB) Lactobacillus delbrueckii ssp. bulgaricus and Streptococcus thermophilus (Mater et al., 2005). Flavor (taste and odor) is a characteristic property of food that influences consumer acceptance and is also associated with feelings of wellbeing (Routray and Mishra, 2011).

Several flavor compounds have been isolated from natural yogurts. The predominant ones are lactic acid, which imparts an acidic, refreshing taste, and a mixture of various carbonyl compounds such as acetaldehyde, ethanol, acetone, diacetyl, and 2-butanone. Among these, acetaldehyde is considered to be the major flavor compound contributing to the typical yogurt aroma reported by several researchers (Ott et al., 1997; Chaves et al., 2002).

Although each of these carbonyl compounds constitutes a recognizable aroma in their own right, yogurt flavor is determined by a balanced mixture of the most important volatile compounds. Both the ratio of different flavor compounds and their overall quantity affect yogurt flavor. For example, a ratio of 2:8 for acetaldehyde and acetone is considered optimum (Gardini et al., 1999; Chaves et al., 2002). The effect of a particular compound on the character of the aroma is determined by its concentration in the end product and its threshold value in any given matrix (Imhof et al., 1995).

Lactobacillus delbrueckii ssp. bulgaricus and Strep. thermophilus are known to be the most important species producing volatile organic aroma compounds in yogurt (Smit et al., 2005). These 2 microorganisms 
act together to produce the volatile molecules associated with flavor development (Courtin and Rul, 2004). Despite this, a great number of volatile organic compounds identified in yogurt originate from the milk and are not produced by the starter culture (Beshkova et al., 1998). Production of acetaldehyde by both bacterial species is isolate dependent; some authors report that Strep. thermophilus produces more acetaldehyde than L. delbrueckii ssp. bulgaricus (Ott et al., 1997), and other authors find the opposite (Pette and Lolkema, 1950; Schirch et al., 1985; Gezginc et al., 2015).

Flavor compounds are produced by carbohydrate fermentation in LAB and some potential pathways for acetaldehyde synthesis have been proposed (Cheng, 2010; Steele et al., 2013; Chen et al., 2017). Some flavor compounds are also produced by AA conversion in LAB via 2 steps: proteolysis and AA degradation. The third production pathway for flavor compounds in LAB is from lipids. It is possible that several metabolic pathways could lead to the formation of flavor compounds: (1) directly via pyruvate decarboxylase or pyruvate oxidase during fermentation or (2) indirectly by the formation of the intermediate acetyl coenzyme A by pyruvate dehydrogenase or pyruvate formate lyase or (3) via another pathway.

Previous studies have shown that acetaldehyde formation in Strep. thermophilus is catalyzed by threonine activity enzyme activity (interconversion of threonine into acetaldehyde and glycine) of serine hydroxyl methyl transferase (EC 2.1.2.1), encoded by the glyA gene (Chaves et al., 2002). Many LAB NADH oxidases, encoded by the nod gene, can switch metabolic route to produce different end compounds (Hugenholtz and Kleerebezem, 1999). Glucose was shown to be the main precursor of acetaldehyde, accounting for $>90 \%$ of labeled acetaldehyde in $L$. delbrueckii ssp. bulgaricus and close to $100 \%$ in Strep. thermophilus (Ott et al., 2000).

To increase consumer acceptance and the competitiveness of production, scientific research to optimize selection of starter cultures is required. For fermented milk products it is particularly important to select LAB starter cultures with excellent flavor characteristics. However, phenotypic analysis of fermentation characteristics and other functional traits is time consuming, especially when a large number of bacteria are to be tested at the same time and when several different production characteristics (e.g., fermentation time, viable counts, volatile components, sensory characteristics of yogurt, synthesis of compounds of interest) are to be determined.

With an increasing number of sequenced LAB genomes available, the functional properties of $\mathrm{LAB}$ isolates can be studied more easily at the molecular level. To the best of our knowledge 22 complete genome sequences of Strep. thermophilus have been published to date (http://www.ncbi.nlm.nih.gov/genome/420). These provide an opportunity to comprehensively understand the relationship between functional genes and phenotypic characteristics.

In the present study, a total of 30 isolates of Strep. thermophilus with different acetaldehyde production characteristics were investigated; specifically, the phenotypic characteristics of each isolate were quantified and related to phylogenic groupings of key functional genes thought to be involved in flavor formation. Among the many functional genes associated with yogurt fermentation and acid production described in the literature, we selected 7 genes for which key function analysis had already been performed on the metabolic pathways associated with flavor formation; these genes are involved in acidification rate, flavor formation, and survival of Strep. thermophilus during yogurt storage (Chaves et al., 2002; Smit et al., 2005; Sander, 2009; Cheng, 2010; Sieuwerts et al., 2010). Using multilocus sequence typing (MLST) analysis we aimed to relate the phylogeny of these genes to the observed phenotypes of the isolates. The results of this study provide an indication of whether genetic screening based on MLST could be used as a rapid screening process to identify isolates of Strep. thermophilus with optimal acetaldehyde production properties. We also aimed to elucidate the relationship between acetaldehyde production and functional genes in phylogenetic clusters.

\section{MATERIALS AND METHODS}

\section{Substrates and Chemical Reagents}

Acetaldehyde was purchased from Sigma Chemical Co. (St. Louis, MO). Skim milk powder was purchased from NZMP Ltd. (Wellington, New Zealand). Media for culturing Strep. thermophilus were M17 Agar (CM0785B, Oxoid, UK) and M17 Broth (CM0817B, Oxoid) purchased from Thermo Fisher Biochemicals (Beijing) Ltd. (Bejing, China).

\section{Isolates and Culture Conditions}

A total of 30 wild Strep. thermophilus isolates were selected and characterized in this study (Table 1). They originated from 18 geographical locations in China and Mongolia, and one was a reference isolate (L822) used as a commercial starter culture in China (unknown origin). Stock cultures were stored at $-80^{\circ} \mathrm{C}$ in $20 \%$ (vol/vol) glycerol. Working cultures were prepared from frozen stock in M17 Broth (Oxoid); each isolate was 


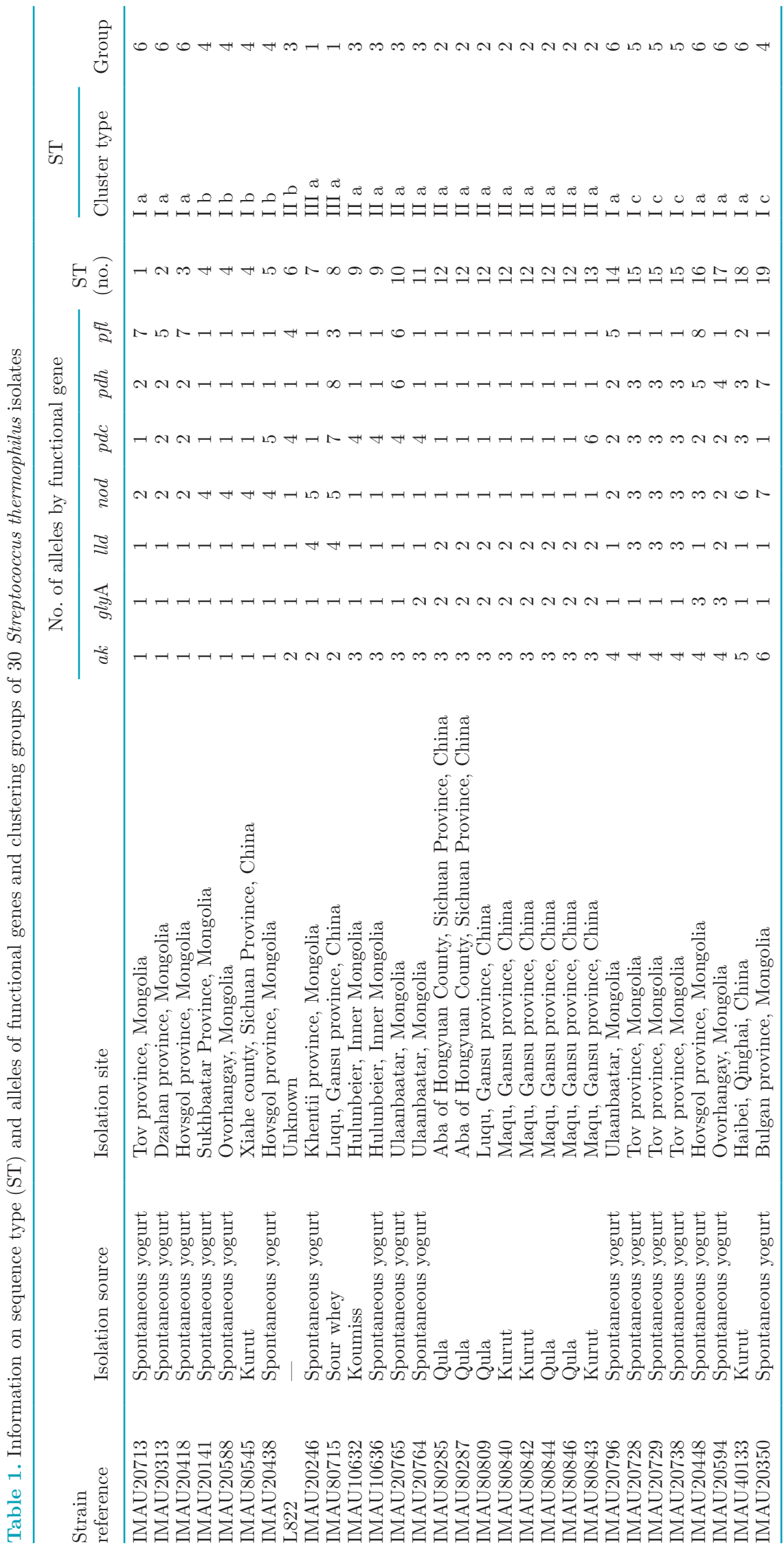


incubated at $37^{\circ} \mathrm{C}$ for 16 to $18 \mathrm{~h}$, without shaking, and subcultured twice at 16- to 18-h intervals before use.

\section{Milk Fermentation}

Fermentation characteristics of all isolates were individually evaluated in milk prepared by adding $1.0 \%$ glucose to $10 \%$ reconstituted skim milk. The milk was sterilized at $95^{\circ} \mathrm{C}$ for $10 \mathrm{~min}$ and cooled to $42^{\circ} \mathrm{C}$. For each isolate evaluated $5 \mathrm{~mL}$ of a $1 \times 10^{7} \mathrm{cfu} / \mathrm{mL}$ suspension was inoculated, as a starter culture, into each of 5 flasks containing $250 \mathrm{~mL}$ of the prepared milk. Fermentation was allowed to proceed at $42^{\circ} \mathrm{C}$ until either the $\mathrm{pH}$ reached 4.6 to 4.7 or the titratable acidity reached $80^{\circ} \mathrm{T}$; the elapsed time was recorded (Wang et al., 2009). Experiments were repeated 3 times. The resulting yogurts were then stored at $4^{\circ} \mathrm{C}$ for $48 \mathrm{~h}$. The $\mathrm{pH}$ and titratable acidity were measured during fermentation and storage time. In addition, the acetaldehyde concentration was measured during storage, as described below.

Analysis of $p H$ and Titratable Acidity. Samples $(25 \mathrm{~mL})$ were taken every $2 \mathrm{~h}$ during fermentation and the $\mathrm{pH}$ and titratable acidity determined in triplicate to determine how fermentation was progressing. During the storage time, the $\mathrm{pH}$ and titratable acidity was also detected every $12 \mathrm{~h}$. The $\mathrm{pH}$ was measured using a pH meter (Mettler Toledo, Zurich, Switzerland) and titratable acidity $\left({ }^{\circ} \mathrm{T}\right)$ was determined after mixing the sample $(9.0 \mathrm{~g})$ with $10 \mathrm{~mL}$ of distilled water and titrating it with $0.1 \mathrm{~N} \mathrm{NaOH}$ using a $0.5 \%$ phenolphthalein indicator to an end point (faint pink color: National Standards of the People's Republic of China, 1996).

Analysis of Acetaldehyde Content. Samples of fermented milk $(5 \mathrm{~g})$ were taken at the end of fermentation $(0 \mathrm{~h})$ and after $12,24,36$, and $48 \mathrm{~h}$ of storage. Citric acid $(20 \%, \mathrm{wt} / \mathrm{vol})$ was added $(0.5 \mathrm{~mL})$ to each sample and the suspension diluted with sterile distilled water to a final volume of $15 \mathrm{~mL}$. After mixing, the suspension was centrifuged at $4^{\circ} \mathrm{C}$ at $4,200 \times g$ for $10 \mathrm{~min}$. The acetaldehyde concentration in the supernatant was determined spectrophotometrically using an acetaldehyde determination kit K-ACHYD (Megazyme, Bray, Ireland) following the manufacturer's instructions. This method is based on the enzymatic (acetaldehyde dehydrogenase) reduction of NAD to NADH and recorded as the absorbance at $340 \mathrm{~nm}$ (Chaves et al., 2002). Based on acetaldehyde levels, we allocated isolates to high-, medium-, and low-producing groups as described in previous studies (Sandine et al., 1972; Saint-Eve et al., 2006; Routray and Mishra, 2011). The isolates in the high groups produced more than $10 \mathrm{mg} / \mathrm{L}$ of acetaldehyde after 24 or $36 \mathrm{~h}$ of storage; medium groups produced 5 to $10 \mathrm{mg} / \mathrm{L}$; and low groups produced less than $5 \mathrm{mg} / \mathrm{L}$.

Statistical Analyses. Statistical analysis of data was done using SAS 16.0 (SAS Institute Inc., Cary, NC). Acetaldehyde concentration was evaluated in triplicate and results expressed as means \pm standard deviation. Statistical analysis was performed by a $t$-test. For each isolate grouping, 3 pairwise Mann-Whitney comparisons were done at each different storage time.

\section{Comparing Genetic Variability in 7 Functional Genes in Different Isolates of Strep. thermophilus}

DNA Extraction. The DNA was extracted from each isolate according to the protocol of Liu et al. (2012). The quality of the extracted DNA was assessed by $0.8 \%$ agarose gel electrophoresis, and the optical density at 260/280 nm was measured by spectrophotometry. All DNA samples were stored at $-20^{\circ} \mathrm{C}$ before processing.

Functional Gene Selection and Primer Design. Primers for MLST analysis were based on the intragenic regions of 7 genes selected for their functional involvement in acetaldehyde synthesis and pyruvate metabolism (Table 2). Seven selected functional genes were evenly distributed on the chromosome of Strep. thermophilus. The amplicon by these primers were used for MLST analysis of Strep. thermophilus strains.

PCR Amplification and MLST Sequencing. The reaction volume for PCR amplification was $50 \mu \mathrm{L}$ and contained $150 \mathrm{ng}$ of genomic DNA, $10 \mathrm{mM}$ of each dNTP, 10 pmol of each primer, and $2.5 \mathrm{U}$ of Taq polymerase in $1 \times$ PCR buffer (with $\mathrm{Mg}^{2+}$ ). Parameters for thermal cycling were $94^{\circ} \mathrm{C}$ for $5 \mathrm{~min}$; 30 cycles of $94^{\circ} \mathrm{C}$ for $1 \mathrm{~min} ; 55$ to $60^{\circ} \mathrm{C}$ for $0.5 \mathrm{~min}$ (optimal annealing temperature varied depending on what was appropriate for the particular gene); extension at $72^{\circ} \mathrm{C}$ for $1 \mathrm{~min}$; and a final extension of $72^{\circ} \mathrm{C}$ for $10 \mathrm{~min}$. Sequencing of the PCR products was done on the Genome Sequencer FLX454 Titanium System (454 Life Sciences) by the Shanghai Majorbio Bio-Pharm Technology Corporation (Shanghai, China). The same primers were used for PCR and sequencing of both DNA strands.

MLST Data Analysis. Both forward and reverse sequences from each isolate were trimmed, aligned, and analyzed. For each MLST locus, a number was allocated to each distinct combination of alleles for each of the 7 genes using BioNumerics v. 6.0 (Applied Maths, Sint-Martens-Latem, Belgium). Different allelic sequences (with at least one nucleotide difference) were assigned arbitrary numbers. For each isolate, the combination of 7 alleles defined its allelic profile, and a unique allelic profile was designated as a sequence type 
Table 2. Functional gene primers for multilocus sequence typing analysis

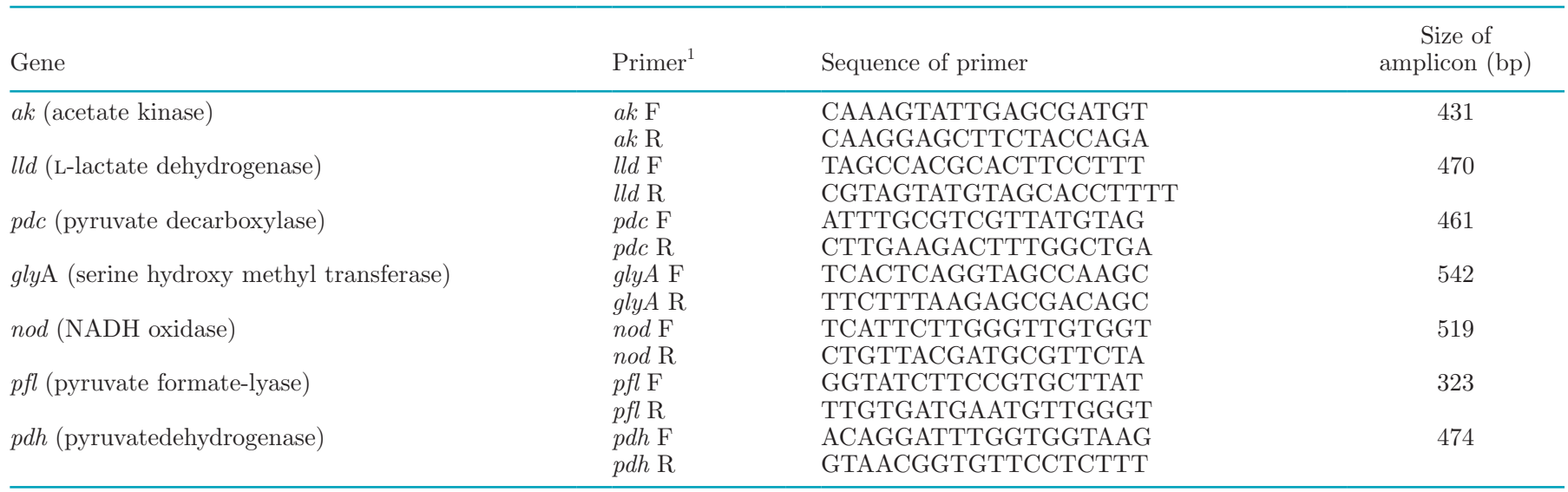

${ }^{1} \mathrm{~F}=$ forward; $\mathrm{R}=$ reverse

(ST). The mean $\mathrm{G}+\mathrm{C}$ content of the DNA, the number of polymorphic sites, and the nucleotide diversity were calculated using Dna SP v. 5.1 (Librado and Rozas, 2009). This software was also used to calculate the ratio of the number of synonymous changes per synonymous site $\left(\mathbf{d}_{\mathbf{S}}\right)$ to the number of nonsynonymous changes per nonsynonymous site $\left(\mathbf{d}_{\mathrm{N}} ; \mathrm{d}_{\mathrm{S}} / \mathrm{d}_{\mathrm{N}}\right.$ ratio $)$ and to perform Tajima's D test.

Linkage equilibrium analysis of the 7 alleles of $I_{A}$ value and $\mathrm{SI}_{A}$ was performed using the LIAN-linkage analysis tool on the MLST website (https://pubmlst .org/databases.shtml; Haubold and Hudson, 2000). To probe evolution and phylogenetic relationships among isolates based on the functional genes for differential acetaldehyde production, a minimum spanning tree was constructed with BioNumerics v 6.0 (Applied Maths). The recombinant analysis of 7 functional genes was done using SplitsTree v 4.10 software (Huson, 1998) on the MLST website (http://eburst.mlst.net/).

A phylogenetic tree was constructed based on sequences of 7 functional genes connected sequentially ( $a k$-lld-pdc-glyA-nod-pfl-pdh) using the neighbor-joining evolution method (Sneath and Sokal, 1973) in the MEGA 4 program (Tamura et al., 2007). The sequences of all alleles were deposited in the EMBL/GenBank databases, and the accession numbers are listed in Table 3. All unique sequences in the 7 genes were assigned an allele number. Clonal complexes (CC) corresponded to groups of ST that differed by only 1 (the single-locus variants) or 2 (the double-locus variants) alleles. In our description we call these CC "groups" because we assigned them by combining genotypic and phenotypic characteristics.

\section{RESULTS}

\section{Change of $\mathrm{pH}$ and Titratable Acidity During Yogurt Storage}

The $\mathrm{pH}$ of yogurt produced by the different isolates declined slightly (from 4.5 to 4.2 ) during storage (Figure 1). The titratable acidity increased to a small extent (Figure 1).

\section{Acetaldehyde Production by Different Strep. thermophilus Isolates in Yogurt During Storage}

The acetaldehyde concentration in yogurt produced by different isolates of Strep. thermophilus varied greatly,

Table 3. Allelic variation in 7 functional genes

\begin{tabular}{|c|c|c|c|c|c|c|c|}
\hline Locus & $\begin{array}{l}\text { Fragment } \\
\text { size (bp) }\end{array}$ & $\begin{array}{l}\mathrm{G}+\mathrm{C} \text { content } \\
\quad(\mathrm{mol} \%)\end{array}$ & $\begin{array}{c}\text { No. of } \\
\text { polymorphic sites }\end{array}$ & $\pi /$ site $^{1}$ & $\mathrm{~d}_{\mathrm{N}} / \mathrm{d}_{\mathrm{S}}^{2}$ & $\begin{array}{l}\text { Tajima's } \\
\text { D value }\end{array}$ & $\begin{array}{l}\text { No. of } \\
\text { alleles }\end{array}$ \\
\hline$\overline{a k}$ & 431 & 43.09 & 6 & 0.00634 & 0.0000 & -1.29615 & 6 \\
\hline$g l y \mathrm{~A}$ & 470 & 44.41 & 2 & - & - & - & 3 \\
\hline nod & 542 & 39.78 & 7 & 0.00439 & 0.3762 & -0.86284 & 7 \\
\hline$p d c$ & 519 & 38.61 & 13 & 0.00881 & 0.3359 & -0.75827 & 7 \\
\hline$p d h$ & 323 & 43.31 & 9 & 0.00614 & 0.5057 & -0.70456 & 8 \\
\hline
\end{tabular}

${ }^{1}$ Mean pairwise nucleotide differences per site.

${ }^{2} \mathrm{~d}_{\mathrm{N}} / \mathrm{d}_{\mathrm{S}}=$ the ratio of nonsynonymous to synonymous substitutions. 

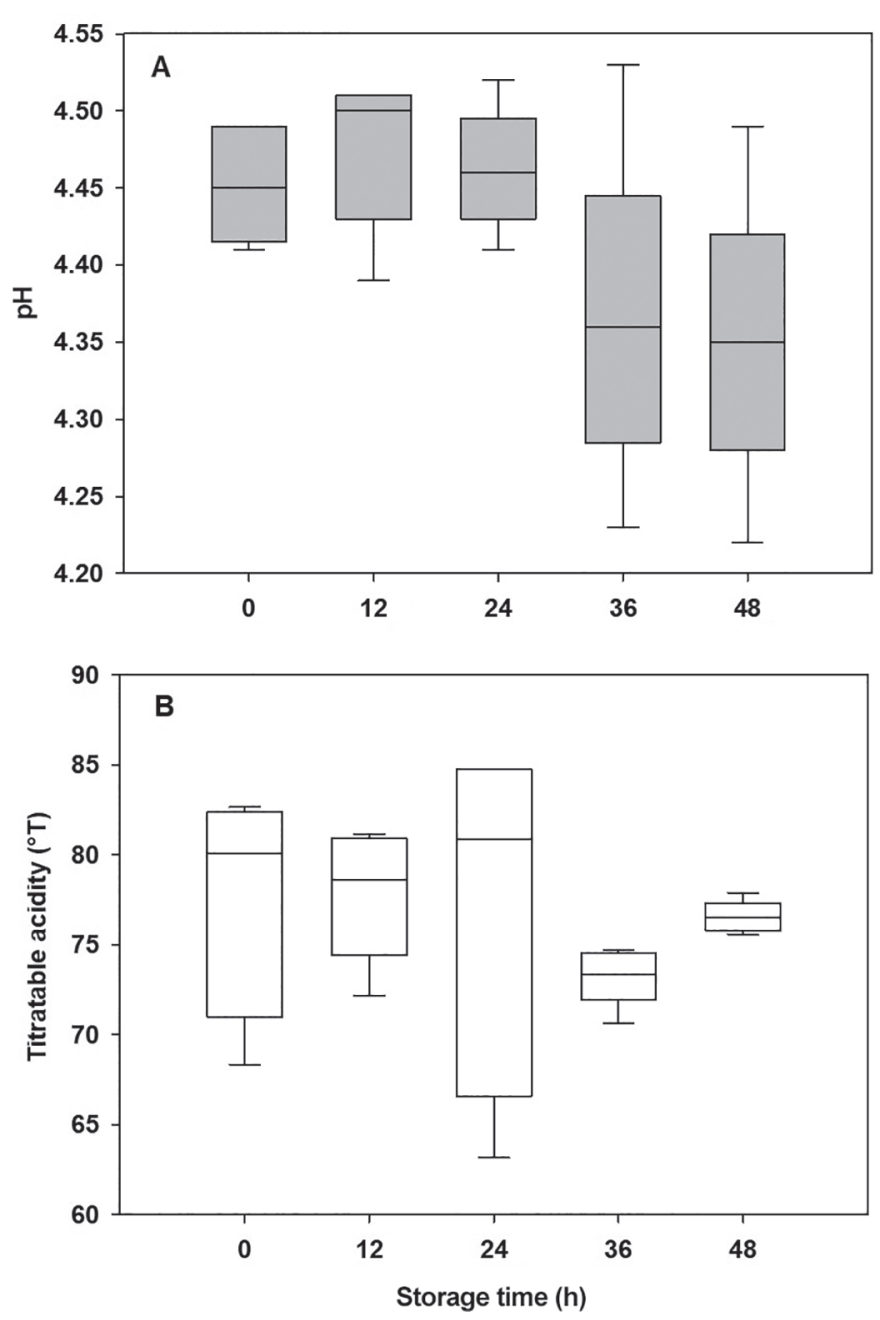

Figure 1. Changes in $\mathrm{pH}$ and titratable acidity of yogurt produced by Streptococcus thermophilus during storage for $48 \mathrm{~h}$. Box $=25$ th and 75 th percentiles; bars $=$ minimum and maximum value; solid line $=$ mean; dotted line $=$ median .

ranging from 1.67 to $16.67 \mathrm{mg} / \mathrm{L}$ during storage. Based on acetaldehyde production, isolates were allocated to a high-yielding group (greater than $10 \mathrm{mg} / \mathrm{L}$ for most of the storage time; Figure 2A); medium-yielding group (5-10 mg/L for most of the storage time; Figure 2B); and low-yielding group (less than $5 \mathrm{mg} / \mathrm{L}$ for most of the storage time; Figure 2C). The acetaldehyde concentration of yogurt produced by group A was greater than $10 \mathrm{mg} / \mathrm{L}$ throughout storage with the exception of only one isolate (L822), which had a value less than $10 \mathrm{mg} / \mathrm{L}$ at some storage time points. In group B (Figure $2 \mathrm{~B}$ ), which contained 10 isolates, the acetaldehyde content of the yogurt produced ranged from 5 to 10 $\mathrm{mg} / \mathrm{L}$ throughout storage, with the exception of only 2 isolates, IMAU80844 and IMAU20713, which produced more than $10 \mathrm{mg} / \mathrm{L}$ at some storage time point. In group $\mathrm{C}$ (Figure $2 \mathrm{C}$ ), which contained 10 isolates, the acetaldehyde concentration varied little during storage, although for isolates IMAU80715 and IMAU20728, values did exceed $5 \mathrm{mg} / \mathrm{L}$ at a some storage time points. Three pairwise Mann-Whitney comparison corrected $P$-values are shown in Supplemental Table S1 (https: //doi.org/10.3168/jds.2018-16203). The acetaldehyde concentration of isolates in group A was higher than that of group B and group $\mathrm{C}$ at $0 \mathrm{~h}$ of storage $(P=$ $0.0001,0.0003,0.0016)$, at $12 \mathrm{~h}$ of storage $(P=0.0006$, $0.0001,0.0009)$, at $24 \mathrm{~h}$ of storage $(P=0.0002,0.0001$, $0.0003)$, at $36 \mathrm{~h}$ of storage $(P=0.0004,0.0001,0.0211)$, and at $48 \mathrm{~h}$ of storage $(P=0.0018,0.0001,0.0681)$.

\section{Cluster Analysis of Strep. thermophilus Based on Functional Genes and Acetaldehyde Content}

The number of alleles per locus ranged from $3(g l y \mathrm{~A})$ to 8 ( $p d h, p f l$; Table 1$)$. The 30 isolates were assigned to 19 ST. The phylogenetic tree constructed showed that the 30 isolates were separated into 3 clusters and 6 subclusters (Figure 3A). Cluster I had 3 subclusters (subcluster Ia, Ib, and Ic) and contained 15 isolates; cluster II had 2 subclusters (subcluster IIa and IIb) and contained 13 isolates; and cluster III had a single subcluster (subcluster IIIa) and contained 2 isolates.

These clusters were distinguishable from each other by combining genetic analysis (functional gene sequences) and the phenotypic characteristic of acetaldehyde production during storage. Cluster I included low-yielding isolates (Figure 3B); they produced less than $10 \mathrm{mg} / \mathrm{L}$ throughout storage with the exception of IMAU20594, IMAU20713, and IMAU20588, where maximum values exceeded $10 \mathrm{mg} / \mathrm{L}$ at some storage time points (mean $\pm \mathrm{SD}): 11.67 \pm 0.32(8 \mathrm{~h}), 10.70 \pm 0.16(24 \mathrm{~h}), 11.14$ $\pm 0.04(36 \mathrm{~h}), 11.70 \pm 0.04(8 \mathrm{~h}), 13.17 \pm 0.16(24 \mathrm{~h})$, and $14.34 \pm 0.16(36 \mathrm{~h})$. Isolates in cluster II were highyielding isolates (more than $10 \mathrm{mg} / \mathrm{L}$ throughout storage) with the exception of IMAU80809, which produced maximum values of only $8.47 \pm 0.20(8 \mathrm{~h})$ and $8.92 \pm$ $0.02(36 \mathrm{~h})$ at some storage time points. Cluster III comprised only 2 isolates: one was a medium-yielding isolate, with maximum values of $7.78(8 \mathrm{~h})$ and $9.48 \pm$ $0.43(24 \mathrm{~h})$, and the other was a low-yielding isolate, with a maximum value of $4.67 \pm 0.40(24 \mathrm{~h})$.

\section{MLST Loci and Allelic Diversity}

Nonsynonymous substitutions per nonsynonymous site were relatively rare compared with synonymous changes per synonymous site (Table 3 ); the $d_{N} / d_{S}$ ranged from 0.000 (for $a k$ gene) to 0.5057 (for $p d h$ gene) in this study. All of these genes showed negative Tajima's D values (Tajima, 1989), and no significant differences among them existed, which indicated selec- 

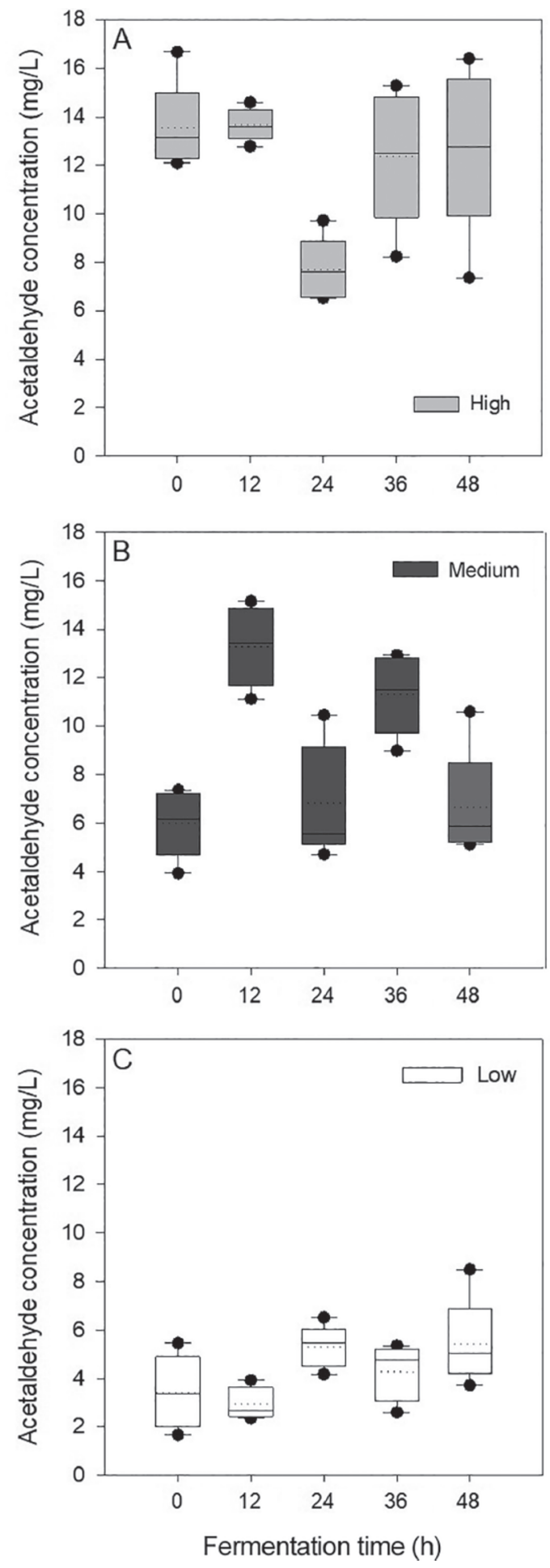

Figure 2. Variability in acetaldehyde production by Streptococcus thermophilus isolates in yogurt during storage for $48 \mathrm{~h}$. Panel A represents the high-acetaldehyde-content group, panel B represents the medium-acetaldehyde-content group, and panel $\mathrm{C}$ represents the lowacetaldehyde-content group. Isolates were classified as high-producing (>10 mg/L, $\mathrm{n}=10)$, medium-producing ( $5-10 \mathrm{mg} / \mathrm{L}, \mathrm{n}=10)$, and low-producing strains $(<5 \mathrm{mg} / \mathrm{L}, \mathrm{n}=10)$. Box $=25$ th and 75 th percentiles; bars $=$ minimum and maximum value; solid line $=$ mean; dotted line $=$ median tion was not based on observed allelic diversity, as is typically observed for functional genes.

\section{Phylogenetic Relationships Among Strep. thermophilus Isolates in Relation to Acetaldehyde Content}

The 30 Strep. thermophilus isolates were characterized based on genotype (functional gene sequences) and phenotype (acetaldehyde content) after different storage times. Although acetaldehyde production by Strep. thermophilus varied with storage time, the clusters formed based on gene sequence followed the same trend at each time point. Because the trends of phylogenetic development were similar, and acetaldehyde production was generally greatest after $24 \mathrm{~h}$ of storage, here we only describe the genetic evolutionary trends for Strep. thermophilus as a minimum-spanning tree constructed from functional genes and acetaldehyde production after $24 \mathrm{~h}$ (Figure 4). The 30 isolates were divided into 19 ST; every circle represents an ST (Figure 4). Of these, $15 \mathrm{ST}$ were each represented by a single isolate; 2 ST (ST18, ST4) were represented by 3 isolates; ST8 was represented by 5 isolates; and ST5 was represented by 2 isolates. These ST could be placed into 4 different $\mathrm{CC}$ : $\mathrm{CC} 1, \mathrm{CC} 2, \mathrm{CC} 3$, and $\mathrm{CC} 4$. Isolates belonging to the same CC were more closely related to each other genetically. Based on a combination of functional gene sequences and the acetaldehyde production analysis, these CC were grouped into different acetaldehyde-producing isolates. Thus, the 30 isolates could be further separated into 6 groups. Group 1 included ST1 and ST2, which were predicted to be ancestral genotypes as they lay at the root of the minimum-spanning tree. Group 4 included ST3, ST4, and ST11, with isolates that had a variety of traits; some were high-yielding isolates and some were low-yielding isolates. In terms of phylogenetic tree development, group 4 belonged to an intermediate node. Groups 3 and 6 included 4 and 6 ST, respectively, and, similar to group 4 , both of these groups had a mixture of high- and low-yielding isolates. In contrast, group 5, which included ST17 and ST18, contained mainly low-yielding isolates, and group 2, which included ST8 and ST9, contained mainly highyielding isolates. From these results we were able to determine the genetic evolution of functional genes in Strep. thermophilus; the ancestral isolates (positioned at the intermediate nodes of the minimum split tree) with medium acetaldehyde production attributes led to the formation of isolates with a range of phenotypic characteristics through genetic differentiation of functional genes under environmental stress acclimation or genetic selection pressure during natural yogurt production. 
A

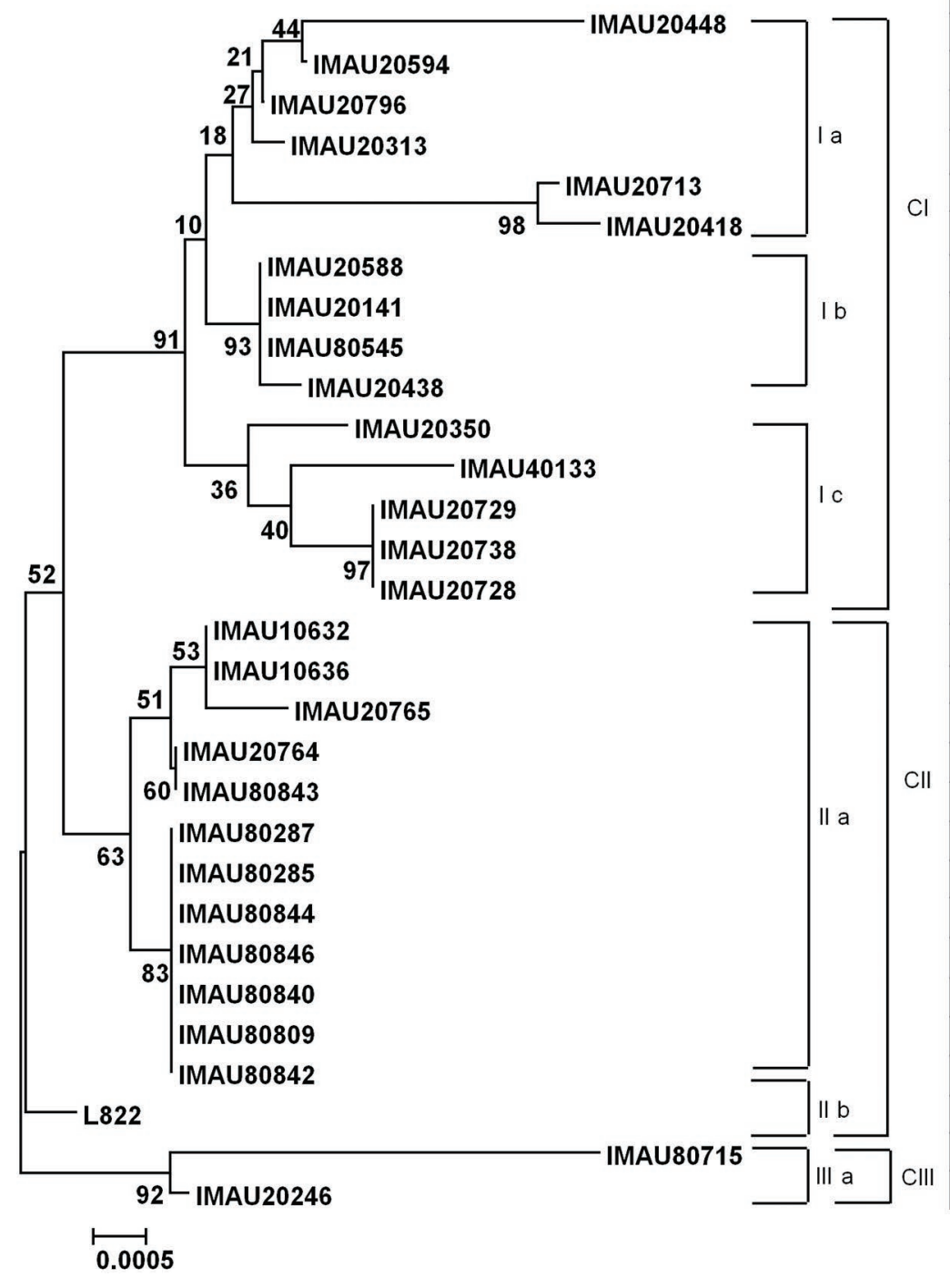

B

\begin{tabular}{|c|l|l|l|}
\hline Strain & $\begin{array}{c}\text { Acetaldehyde } \\
\text { (8 hour) }\end{array}$ & $\begin{array}{c}\text { Acetaldehyde } \\
\text { (24 hour) }\end{array}$ & $\begin{array}{c}\text { Acetaldehyde } \\
\text { (36 hour) }\end{array}$ \\
\hline IMAU20448 & $6.53 \pm 0.20$ & $4.61 \pm 0.16$ & $5.53 \pm 0.43$ \\
\hline IMAU20594 & $11.67 \pm 0.32$ & $10.70 \pm 0.19$ & $3.47 \pm 0.20$ \\
\hline IMAU20796 & $3.47 \pm 0.20$ & $6.11 \pm 0.40$ & $4.81 \pm 0.12$ \\
\hline IMAU20313 & $5.45 \pm 0.23$ & $4.17 \pm 0.00$ & $6.50 \pm 0.24$ \\
\hline IMAU20713 & $9.73 \pm 0.39$ & $11.14 \pm 0.04$ & $7.64 \pm 0.20$ \\
\hline IMAU20418 & $6.37 \pm 0.43$ & $5.31 \pm 0.04$ & $5.84 \pm 0.39$ \\
\hline IMAU20588 & $11.70 \pm 0.04$ & $13.17 \pm 0.16$ & $14.34 \pm 0.16$ \\
\hline IMAU20141 & $4.70 \pm 0.04$ & $5.56 \pm 0.00$ & $10.45 \pm 0.63$ \\
\hline IMAU80545 & $2.45 \pm 0.47$ & $5.39 \pm 0.16$ & $5.31 \pm 0.43$ \\
\hline IMAU20438 & $6.58 \pm 0.04$ & $6.53 \pm 0.20$ & $7.59 \pm 0.28$ \\
\hline IMAU20350 & $4.75 \pm 0.04$ & $5.34 \pm 0.32$ & $3.56 \pm 0.08$ \\
\hline IMAU40133 & $1.67 \pm 0.69$ & $3.36 \pm 0.04$ & $5.45 \pm 0.16$ \\
\hline IMAU20729 & $3.34 \pm 0.39$ & $2.50 \pm 0.00$ & $3.92 \pm 0.04$ \\
\hline IMAU20738 & $2.86 \pm 0.11$ & $4.28 \pm 0.16$ & $3.70 \pm 0.12$ \\
\hline IMAU20728 & $6.15 \pm 0.10$ & $5.45 \pm 0.16$ & $3.92 \pm 0.04$ \\
\hline IMAU10632 & $11.25 \pm 1.37$ & $11.67 \pm 0.40$ & $11.76 \pm 0.28$ \\
\hline IMAU10636 & $12.78 \pm 0.40$ & $13.36 \pm 0.20$ & $16.39 \pm 0.79$ \\
\hline IMAU20765 & $12.23 \pm 0.39$ & $8.20 \pm 0.19$ & $10.39 \pm 0.62$ \\
\hline IMAU20764 & $14.37 \pm 0.30$ & $12.5 \pm 0.00$ & $8.23 \pm 0.23$ \\
\hline IMAU80843 & $16.67 \pm 0.10$ & $12.09 \pm 0.98$ & $13.31 \pm 0.35$ \\
\hline IMAU80287 & $13.61 \pm 0.40$ & $14.00 \pm 0.28$ & $13.42 \pm 0.28$ \\
\hline IMAU80285 & $14.59 \pm 0.59$ & $12.22 \pm 0.00$ & $11.11 \pm 0.00$ \\
\hline IMAU80844 & $11.50 \pm 0.24$ & $13.09 \pm 0.04$ & $8.06 \pm 0.39$ \\
\hline IMAU80846 & $10.59 \pm 0.43$ & $13.36 \pm 0.04$ & $14.53 \pm 0.51$ \\
\hline IMAU80840 & $13.20 \pm 0.19$ & $13.06 \pm 0.78$ & $9.86 \pm 0.20$ \\
\hline IMAU80809 & $8.47 \pm 0.20$ & $8.92 \pm 0.20$ & $10.50 \pm 0.47$ \\
\hline IMAU80842 & $12.92 \pm 0.59$ & $12.70 \pm 0.28$ & $10.45 \pm 0.63$ \\
\hline L822 & $14.59 \pm 0.59$ & $12.22 \pm 0.00$ & $11.11 \pm 0.00$ \\
\hline IMUA80715 & $5.28 \pm 0.03$ & $5.03 \pm 0.04$ & $4.67 \pm 0.40$ \\
\hline IMAU20246 & $10.70 \pm 0.19$ & $7.78 \pm 0.40$ & $9.48 \pm 0.43$ \\
\hline
\end{tabular}

Figure 3. Relationships between phylogeny and phenotypic characteristics of Streptococcus thermophilus isolates using the neighbor-joining method. (A) The phylogenetic tree was constructed based on the functional gene sequences; IMAU is the strain number. C = cluster. (B) The acetaldehyde concentration $(\mathrm{mg} / \mathrm{L}$; mean $\pm \mathrm{SD}$ ) produced by each isolate. The concentrations were more than $10 \mathrm{mg} / \mathrm{L}$ (red) or less than 5 $\mathrm{mg} / \mathrm{L}$ (blue), or ranged from 5 to $10 \mathrm{mg} / \mathrm{L}$ (green).

\section{Nucleotide Variation in Alleles and Changes of AA Sequence of the Protein}

A total of 63 polymorphic sites existed in 7 genes; among these, there were 30 missense mutations in 5 genes. These mutations occurred in only a few isolates $(1,2$, or 3 isolates) and were not formed as a specific rule. Interestingly, 3 nonsynonymous mutation sites existed in 3 genes ( $\mathrm{G}$ to $\mathrm{T}$ in glyA; $\mathrm{G}$ to $\mathrm{A}$ in $l l d$; and $\mathrm{G}$ to $\mathrm{T}$ in nod) from all the high-yielding isolates, except IMAU80809. These changes in nucleotide sequence lead to the different AA sequence variation (namely A to S; E to K; and G to T; Table 4).

\section{DISCUSSION}

Flavor is one of the most important properties of any food product and an important factor determining acceptability and preference. The production of acetaldehyde by Strep. thermophilus is a very important characteristic in dairy product production. The acetaldehyde content of yogurt during storage varied 
significantly among the isolates we studied. This means that changes in acetaldehyde content are isolate specific. Most studies in the literature report levels of acetaldehyde in yogurt that range between 10 and $15 \mu \mathrm{g} / \mathrm{g}$ (equivalent to $\mathrm{mg} / \mathrm{L}$; Beshkova et al., 1998; Routray and Mishra, 2011), although Tamime and Deeth (1980) reported levels between 2.5 and $37.5 \mathrm{ppm}$ (equivalent to $\mathrm{mg} / \mathrm{L})$. Many researchers believe that the acetaldehyde content of yogurt could range from 8 to $50 \mathrm{mg} / \mathrm{L}$ (Ršic and Kurmann, 1978; Imhof and Bosset, 1994; Chen et al., 2017). Highest concentrations of acetaldehyde (in the range of 5 to $21 \mathrm{mg} / \mathrm{L}$ ) are due to its low utilization rate in $\mathrm{LAB}$, which lack the alcohol dehydrogenase enzyme responsible for conversion of acetaldehyde to ethanol (Chaves et al., 2002). Yogurt with poor flavor has less than $4.0 \mathrm{mg} / \mathrm{L}$ of acetaldehyde (which is considered to be a suboptimal amount), whereas yogurt with good flavor has greater than $8.0 \mathrm{mg} / \mathrm{L}$ of acetaldehyde (Sandine et al., 1972). Beshkova et al. (1998) measured the production of flavor compounds when mixed starter cultures were used for lactic acid fermentation and found that the maximum concentration of flavor compounds was achieved within 22 to $31 \mathrm{~h}$ of the cooling stage. Thus, we analyzed the relationship between acetaldehyde content and functional genes of Strep. thermophilus at 36 and $48 \mathrm{~h}$. In the present study the 30 isolates could be divided into 3 groups based on the acetaldehyde content of the yogurt during storage. This methodology for grouping may better reflect their contribution to the flavor of yogurt.

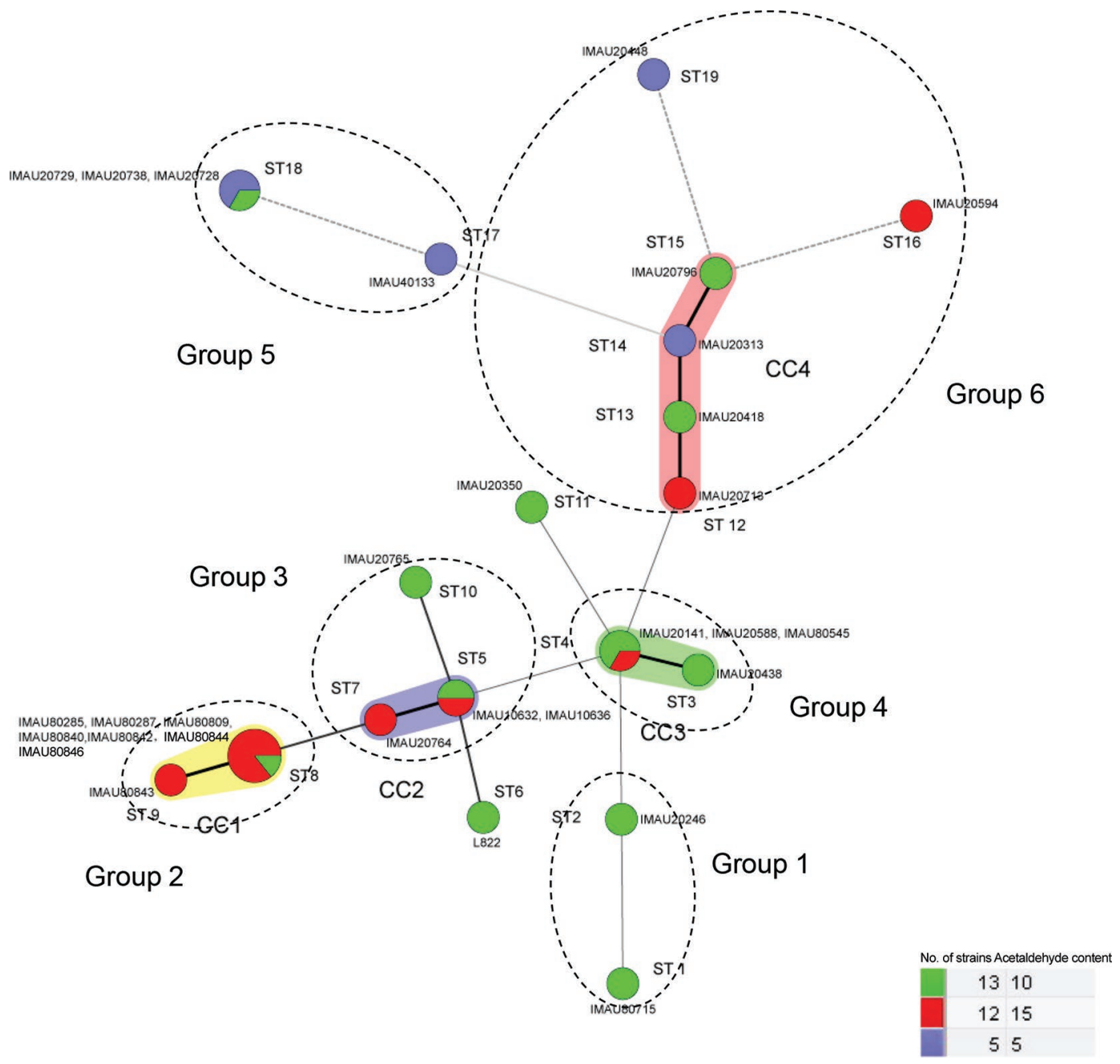

Figure 4. Minimum split tree for Streptococcus thermophilus based on functional gene sequences and acetaldehyde concentration in yogurt during storage. IMAU is the strain number. Green circles correspond to medium-acetaldehyde-production isolates (approximately 10 mg/L), red circles to high-acetaldehyde-production isolates (approximately $15 \mathrm{mg} / \mathrm{L}$ ), and blue circles to low-acetaldehyde-production isolates (approximately $5 \mathrm{mg} / \mathrm{L}$ ). The size of the circles is proportional to the number of isolates belonging to each sequence type (ST). Clonal complexes (CC) are indicated in a different color. Combining CC and acetaldehyde production allowed further separation into different groups. Group 1 is predicted to be the ancestral genotype of the major CC. 
Differences in the flavor-active compounds in yogurt compared with milk are most likely to be due to the metabolism of the LAB. These culture-generated aroma compounds result from microbial, enzymatic, or chemical transformations of lactose, lipids, citric acid, and proteins or AA present in milk (Tamime and Robinson, 1999; McGorrin, 2001; Boelrijk et al., 2003). During storage, the volatile constituents of yogurt can change depending on the starter culture, formulation, and storage conditions (Tamime and Deeth, 1980; Kneifel et al., 1992). However, with respect to acetaldehyde content, the most important determining factors are LAB isolate characteristics, particularly their genetic basis. In general, there are 3 major pathways for the production of flavor constituents in yogurt: (1) degradation pathways of milk fat; (2) lactate metabolic pathways; and (3) citrate metabolic pathways (McSweeney and Sousa, 2000; Cheng, 2010). During fermentation, bacteria perform 3 major biochemical conversions of milk components: first, conversion of carbohydrate into lactic acid or other metabolites (glycolysis); second, hydroly- sis of caseins into peptides and free AA (proteolysis); and third, breakdown of milk fat into free fatty acids (lipolysis; Steele et al., 2013; Smid and Kleerebezem, 2014; Chen et al., 2017).

In recent years, it has become possible to screen microorganisms based on genotype using microbial genome sequencing. In general, the complete genome of the microorganism is sequenced and then functional genes and gene clusters located through comparative genomics sequence analysis tools, to elucidate the relationships between genes or gene clusters and phenotypic characteristics. However, to our knowledge no studies until ours relate specific phenotypic traits with multiple genes active in the metabolic pathway of interest. No multiple gene screening methods have been developed, and genetic evolution and phylogenetic clustering analysis based on the characteristics and functional gene sequences has not been described previously.

In the present study, 7 functional genes associated with acetaldehyde production during pyruvate metabolism were selected and evaluated using MLST in 30

Table 4. Nucleotide variation in alleles and change in AA sequences of proteins ${ }^{1}$

\begin{tabular}{|c|c|c|c|c|c|c|c|c|c|c|c|c|}
\hline \multirow[b]{3}{*}{ Item } & \multicolumn{4}{|c|}{ gly } & \multicolumn{4}{|c|}{$l l d$} & \multicolumn{4}{|c|}{ nod } \\
\hline & \multicolumn{3}{|c|}{ Nucleotide, site } & \multirow{2}{*}{$\begin{array}{c}\begin{array}{c}\text { Protein, } \\
\text { site }\end{array} \\
71\end{array}$} & \multicolumn{3}{|c|}{ Nucleotide, site } & \multirow{2}{*}{$\begin{array}{c}\begin{array}{c}\text { Protein, } \\
\text { site }\end{array} \\
138\end{array}$} & \multicolumn{3}{|c|}{ Nucleotide, site } & \multirow{2}{*}{$\begin{array}{c}\begin{array}{c}\text { Protein, } \\
\text { site }\end{array} \\
15\end{array}$} \\
\hline & 211 & 212 & 213 & & 421 & 422 & 423 & & 43 & 44 & 45 & \\
\hline IMAU10632 & G & $\mathrm{C}$ & A & $\mathbf{A}$ & G & $\mathrm{A}$ & $\mathrm{A}$ & $\mathbf{E}$ & $\mathrm{G}$ & $\mathrm{T}$ & $\mathrm{C}$ & $V$ \\
\hline IMAU10636 & G & $\mathrm{C}$ & A & $\mathbf{A}$ & G & $\mathrm{A}$ & $\mathrm{A}$ & $\mathbf{E}$ & $\mathrm{G}$ & $\mathrm{T}$ & $\mathrm{C}$ & $V$ \\
\hline IMAU20313 & G & $\mathrm{C}$ & A & A & G & A & A & $\mathbf{E}$ & $\mathrm{G}$ & G & $\mathrm{C}$ & G \\
\hline IMAU20350 & G & $\mathrm{C}$ & A & $\mathbf{A}$ & G & $\mathrm{A}$ & A & $\mathbf{E}$ & $\mathrm{G}$ & $\mathrm{G}$ & $\mathrm{C}$ & G \\
\hline IMAU20418 & G & $\mathrm{C}$ & A & A & G & A & A & $\mathbf{E}$ & $\mathrm{G}$ & $\mathrm{G}$ & $\mathrm{C}$ & G \\
\hline IMAU20438 & G & $\mathrm{C}$ & A & A & G & A & A & $\mathbf{E}$ & $\mathrm{G}$ & $\mathrm{G}$ & $\mathrm{C}$ & G \\
\hline IMAU20448 & G & $\mathrm{C}$ & A & A & G & A & A & $\mathbf{E}$ & $\mathrm{G}$ & $\mathrm{G}$ & $\mathrm{C}$ & G \\
\hline IMAU20588 & $\mathrm{G}$ & $\mathrm{C}$ & A & $\mathbf{A}$ & $\mathrm{G}$ & $\mathrm{A}$ & $\mathrm{A}$ & $\mathbf{E}$ & $\mathrm{G}$ & $\mathrm{G}$ & $\mathrm{C}$ & G \\
\hline IAMU20594 & G & $\mathrm{C}$ & A & $\mathbf{A}$ & G & $\mathrm{A}$ & $\mathrm{A}$ & $\mathbf{E}$ & $\mathrm{G}$ & $\mathrm{G}$ & $\mathrm{C}$ & G \\
\hline IMAU20769 & $\mathrm{G}$ & $\mathrm{C}$ & A & A & G & A & A & $\mathbf{E}$ & $\mathrm{G}$ & $\mathrm{G}$ & $\mathrm{C}$ & G \\
\hline IMAU40133 & G & $\mathrm{C}$ & A & A & G & A & A & $\mathbf{E}$ & $\mathrm{G}$ & G & $\mathrm{C}$ & G \\
\hline IMAU80545 & G & $\mathrm{C}$ & A & A & G & A & A & $\mathbf{E}$ & $\mathrm{G}$ & $\mathrm{T}$ & $\mathrm{C}$ & $V$ \\
\hline IMAU80715 & G & $\mathrm{C}$ & A & A & G & A & A & $\mathbf{E}$ & $\mathrm{G}$ & $\mathrm{T}$ & $\mathrm{C}$ & $V$ \\
\hline L822 & G & $\mathrm{C}$ & A & A & G & A & A & $\mathbf{E}$ & $\mathrm{G}$ & $\mathrm{T}$ & $\mathrm{C}$ & $V$ \\
\hline IMAU80287 & $\mathrm{T}$ & $\mathrm{C}$ & A & $S$ & A & A & A & $K$ & $\mathrm{G}$ & $\mathrm{T}$ & $\mathrm{C}$ & $V$ \\
\hline IMAU20764 & $\mathrm{T}$ & $\mathrm{C}$ & A & $S$ & A & A & A & $K$ & $\mathrm{G}$ & $\mathrm{T}$ & $\mathrm{C}$ & $V$ \\
\hline IMAU80285 & $\mathrm{T}$ & $\mathrm{C}$ & A & $S$ & A & A & A & $K$ & $\mathrm{G}$ & $\mathrm{T}$ & $\mathrm{C}$ & $V$ \\
\hline IMAU80809 & $\mathrm{T}$ & $\mathrm{C}$ & A & $S$ & A & $\mathrm{A}$ & $\mathrm{A}$ & $K$ & $\mathrm{G}$ & $\mathrm{T}$ & $\mathrm{C}$ & $V$ \\
\hline IMAU80840 & $\mathrm{T}$ & $\mathrm{C}$ & A & $S$ & A & A & A & $K$ & $\mathrm{G}$ & $\mathrm{T}$ & $\mathrm{C}$ & $V$ \\
\hline IMAU80842 & $\mathrm{T}$ & $\mathrm{C}$ & A & $S$ & A & A & A & $K$ & $\mathrm{G}$ & $\mathrm{T}$ & $\mathrm{C}$ & $V$ \\
\hline IMAU80843 & $\mathrm{T}$ & $\mathrm{C}$ & A & $S$ & A & A & A & $K$ & $\mathrm{G}$ & $\mathrm{T}$ & $\mathrm{C}$ & $V$ \\
\hline IMAU80844 & $\mathrm{T}$ & $\mathrm{C}$ & A & $S$ & A & A & A & $K$ & $\mathrm{G}$ & $\mathrm{T}$ & $\mathrm{C}$ & $V$ \\
\hline
\end{tabular}

${ }^{1}$ Bold text means that the sequence nucleotide has been mutated. Italic text means that the AA has been changed in proteins. 
isolates. These selected genes were present as a single copy in all isolates, and the functions of their encoded proteins were preferentially conserved and well characterized (Chaves et al., 2002; Bolotin et al., 2004; Smit et al., 2005; Sander, 2009; Cheng, 2010). From the resulting minimum split-tree, it was possible to differentiate and genetically group isolates with similar phenotypic acetaldehyde production traits and elucidate the functional genetic evolutionary history of the isolates. It is very interesting that the coding sequence of the gly, lld, and nod genes from high-yielding isolates was identical (at base position of 211, 421, and 43), but these bases had been mutated in most of the low- and mediumyielding isolates (Table 4). This base variation leads to changes in AA sequence. Therefore, it is believable that the variation in these functional gene sequences is an important cause of the phenotypic variation, specifically acetaldehyde production by different isolates.

The isolate clusters that could be separated based on sequence differences in functional genes corresponded well with the group separation achieved based on acetaldehyde production. Hence, different isolates with different acetaldehyde production characteristics could be distinguished based on their functional gene sequence analysis. For this reason, the results of this study may provide a methodological foundation for the development of a rapid molecular screening method to select isolates with the best flavor-related phenotypes. Our results suggest that key functional genes related to acetaldehyde synthesis in Strep. thermophilus have undergone genetic differentiation leading to gene-driven variation in metabolism, through a process of genetic selection. We believe that the functional gene sequence data analysis of isolates accurately reflects the phenotypic characteristics of those isolates.

The ratio of $\mathrm{d}_{\mathrm{N}} / \mathrm{d}_{\mathrm{S}}$ was less than one, which indicates that nonsynonymous mutations are harmful and that purifying selection reduces their retention speed. The results were confirmed by evaluation of Tajima's D value. The DNA $\mathrm{G}+\mathrm{C}$ content observed for all alleles from the 7 genes ranged from $38.6 \mathrm{~mol} \%(p d c)$ to 44.4 mol \% (glyA), which was a little higher than that of the complete genomes of Strep. thermophilus isolate LMG18311 ${ }^{\mathrm{T}}(39.1 \mathrm{~mol} \%)$ and Strep. thermophilus isolate ND03 (39.0 mol \%).

\section{CONCLUSIONS}

Multilocus sequence typing analysis was used to elucidate genetic evolution and phylogenic relationships among 30 isolates of Strep. thermophilus based on variability in the sequences of 7 functional genes associated with acetaldehyde production. Groups of isolates separated by MLST were consistent with anal- ysis of phenotypic characteristics. Specifically, high-, medium-, and low-acetaldehyde-yielding isolates were clustered in corresponding groups based on functional gene MLST analysis. The result of the present study shows that Strep. thermophilus with different acetaldehyde production characteristics evolved from ancestral isolates with medium-acetaldehyde-yielding capabilities through genetic evolution and natural selection pressures during yogurt production. Typing of functional gene sequences reflects the ongoing genetic evolutionary process; also, the level of acetaldehyde production of previously unstudied isolates could be predicted from where their functional genes clustered during phylogenetic analysis. From the results of this study, we expect that genetic screening based on MLST could be used as a promising approach to identifying Strep. thermophilus with excellent acetaldehyde production properties. It is interesting that we found the clusters of Strep. thermophilus isolates with similar acetaldehyde production characteristics corresponded with the functional gene phylogenetic groups.

\section{ACKNOWLEDGMENTS}

This research was supported by the National Natural Science Foundation of China (Beijing, Grant No. 31671871, 31471711, 31460446), the Natural Science Foundation of Inner Mongolia (2016JQ04), the Fund for Young Innovative and Entrepreneurial of "Grassland Talents" in Inner Mongolia Autonomous Region (Q 2017066, Program for International S\&T Cooperation Projects of China (ISTCP, 2014DFR31150), the China Agriculture Research System (Grant No. CARS36), and the Natural Science Foundation of Inner Mongolia (2016JQ04). The suggestions and help with the article from Song Yajun (Academy of Military Sciences of China, Beijing) are sincerely appreciated.

\section{REFERENCES}

Astrup, A., 2014. Yogurt and dairy product consumption to prevent cardiometabolic diseases: Epidemiologic and experimental studies. Am. J. Clin. Nutr. 99:1235S-1242S.

Beshkova, D., E. Simova, G. Frengova, and Z. Simov. 1998. Production of flavour compounds by yogurt starter cultures. J. Ind. Microbiol. Biotechnol. 20:180-186.

Boelrijk, A. E. M., C. de Jong, and G. Smit. 2003. Flavour generation in dairy products. Pages 130-154 in Dairy Processing-Improving Quality. G. Smit, ed. CRC Press, Boca Raton, FL.

Bolotin, A., B. Quinquis, P. Renault, A. Sorokin, S. D. Ehrlich, S. Kulakauskas, A. Lapidus, E. Goltsman, M. Mazur, G. D. Pusch, M. Fonstein, R. Overbeek, N. Kyprides, B. Purnelle, D. Prozzi, K. Ngui, D. Masuy, F. Hancy, S. Burteau, M. Boutry, J. Delcour, A. Goffeau, and P. Hols. 2004. Complete sequence and comparative genome analysis of the dairy bacterium Streptococcus thermophilus. Nat. Biotechnol. 22:1554-1558.

Chaves, A. C. S. D., M. Fernandez, A. L. S. Lerayer, I. Mierau, M. Kleerebezem, and J. Hugenholtz. 2002. Metabolic engineering of 
acetaldehyde production by Streptococcus thermophilus. Appl. Environ. Microbiol. 68:5656-5662.

Chen, C., S. Zhao, G. Hao, H. Yu, H. Tian, and G. Zhao. 2017. Role of lactic acid bacteria on the yogurt flavour: A review. Int. J. Food Prop. 20:S316-S330.

Cheng, H. F. V. 2010. Volatile flavour compounds in yogurt: A review. Crit. Rev. Food Sci. Nutr. 50:938-950.

Courtin, P., and F. Rul. 2004. Interactions between microorganisms in a simple ecosystem: Yogurt bacteria as a study model. Lait 84:125-134.

El-Abbadi, N. H., M. C. Dao, and S. N. Meydani. 2014. Yogurt: Role in healthy and active aging. Am. J. Clin. Nutr. 99:1263S-1270S.

Gardini, F., R. Lanciotti, M. E. Guerzoni, and S. Torriani. 1999. Evaluation of aroma production and survival of Streptococcus thermophilus, Lactobacillus delbrueckii ssp. bulgaricus and Lactobacillus acidophilus in fermented milks. Int. Dairy J. 9:125-134.

Gezginc, Y., F. Topcal, S. Comertpay, and I. Akyol. 2015. Quantitative analysis of the lactic acid and acetaldehyde produced by Streptococcus thermophilus and Lactobacillus bulgaricus strains isolated from traditional Turkish yogurts using HPLC. J. Dairy Sci. 98:1426-1434

Haubold, B., and R. R. Hudson. 2000. Lian 3.0: Detecting linkage disequilibrium in multilocus data. Linkage analysis. Bioinformatics 16:847-848.

Hugenholtz, J., and M. Kleerebezem. 1999. Metabolic engineering of lactic acid bacteria: Overview of the approaches and results of pathway rerouting involved in food fermentations. Curr. Opin. Biotechnol. 10:492-497.

Huson, D. H. 1998. SplitsTree: Analyzing and visualizing evolutionary data. Bioinformatics 14:68-73

Imhof, R., and J. O. Bosset. 1994. Quantitative GC-MS-analysis of volatile flavour compounds in pasteurized milk and fermented milk products applying a standard addition method. Lebensm. Wiss. Technol. 27:265-269.

Imhof, R., H. Glälittli, and J. O. Bosset. 1995. Volatile organic compounds produced by thermophilic and mesophilic single strain dairy starter cultures. Lebensm. Wiss. Technol. 28:78-86.

Kneifel, W., F. Ulberth, F. Erhard, and D. Jaros. 1992. Aroma profiles and sensory properties of yogurt and yogurt-related products. I. Screening of commercially available starter cultures. Milchwissenschaft 47:362-365.

Librado, P., and J. Rozas. 2009. DnaSP v5: A software for comprehensive analysis of DNA polymorphism data. Bioinformatics 25:14511452 .

Liu, W., Q. Bao, X. Chen, T. Sun, M. Li, J. Zhang, J. Yu, M. Bilige, T. Sun, and H. Zhang. 2012. Isolation and identification of lactic acid bacteria from Tarag in Eastern Inner Mongolia of China by $16 \mathrm{~S}$ rRNA sequences and DGGE analysis. Microbiol. Res. 167:110-115.

Mater, D. D., L. Bretigny, O. Firmesse, M. J. Flores, A. Mogenet, J L. Bresson, and G. Corthier. 2005. Streptococcus thermophilus and Lactobacillus delbrueckii ssp. bulgaricus survive gastrointestinal transit of healthy volunteers consuming yogurt. FEMS Microbiol. Lett. 250:185-187.

McGorrin. R. J. 2001. Advances in dairy flavour chemistry. Pages 67-84 in Food Flavours and Chemistry: Advances of the New Millennium. A. M. Spanier, F. Shahidi, T. H. Parliment, and C. T. Ho, ed. Royal Soc. Chem., Cambridge, UK.

McSweeney, P. L. H., and M. J. Sousa. 2000. Biochemical pathways for the production of flavour compounds in cheeses during ripening: A review. Lait 80:293-324.

National Standards of the People's Republic of China. 1996. Method for analysis of hygienic standard of milk and milk products. Bulletin 5009.46. Chinese Natl. Stand., Beijing, China.
Ott, A., L. B. Fay, and A. Chaintreau. 1997. Determination and origin of the aroma impact compounds of yogurt flavour. J. Agric. Food Chem. 45:850-858.

Ott, A., J. E. Germond, and A. Chaintreau. 2000. Origin of acetaldehyde during milk fermentation using 13C-labeled precursors. J. Agric. Food Chem. 48:1512-1517.

Pette, J. W., and H. Lolkema. 1950. Yogurt, III: Acid production and aroma formation in yogurt. Neth. Milk Dairy J. 4:261-273.

Rizzoli, R. 2014. Dairy products, yogurts, and bone health. Am. J. Clin. Nutr. 99:1256S-1262S

Routray, W., and H. N. Mishra. 2011. Scientific and technical aspects of yogurt aroma and taste: A review. Compr. Rev. Food Sci. Food Saf. 10:208-220.

Ršic, J. L., and J. Kurmann. 1978. Flavour and aroma in yoghurt. Pages 90-98 in Yoghurt. Scientific Grounds, Technology, Manufacture and Preparations. J. Rasic and J. Kurmann, ed. Tech Dairy Publ. House Distrib., Copenhagen, Denmark.

Saint-Eve, A., A. Juteau, S. Atlan, N. Martin, and I. Souchon. 2006 Complex viscosity induced by protein composition variation influences the aroma release of flavored stirred yogurt. J. Agric. Food Chem. 54:3997-4004

Sander, S. 2009. Analysis of molecular interactions between yoghurt bacteria by an integrated genomics approach. PhD Thesis. Wageningen Univ., Wageningen, the Netherlands.

Sandine, W. E., C. Daly, P. R. Elliker, and E. R. Vedamuthu. 1972 Causes and control of culture related flavour defects on cultured dairy products. J. Dairy Sci. 55:1031-1039.

Schirch, V., S. Hopkins, E. Villar, and S. Angelaccio. 1985. Serine hydroxymethyl transferase from Escherichia coli: Purification and properties. J. Bacteriol. 163:1-7.

Sieuwerts, S., D. Molenaar, S. A. F. T. van Hijum, M. Beerthuyzen, M. J. A. Stevens, P. W. M. Janssen, C. J. Ingham, F. A. M. de Bok, W. M. de Vos, and J. E. T. van Hylckama Vlieg. 2010 Mixed-culture transcriptome analysis reveals the molecular basis of mixed-culture growth in Streptococcus thermophilus and Lactobacillus bulgaricus. Appl. Environ. Microbiol. 76:7775-7784.

Smid, E. J., and M. Kleerebezem. 2014. Production of aroma compounds in lactic fermentations. Annu. Rev. Food Sci. Technol. 5:313-326.

Smit, G., B. A. Smit, and W. J. M. Engels. 2005. Flavour formation by lactic acid bacteria and biochemical flavour profiling of cheese products. FEMS Microbiol. Rev. 29:591-610.

Sneath, P. H. A., and R. R. Sokal. 1973. Numerical Taxonomy. Freeman, San Francisco, CA.

Steele, J., J. Broadbent, and J. Kok. 2013. Perspectives on the contribution of lactic acid bacteria to cheese flavor development. Curr. Opin. Biotechnol. 24:135-141.

Tajima, F. 1989. Statistical method for testing the neutral mutation hypothesis by DNA polymorphism. Genetics 123:585-595.

Tamime, A., and H. Deeth. 1980. Yogurt: Technology and biochemistry. J. Food Prot. 43:939-977.

Tamime, A. Y., and R. K. Robinson. 1999. Yoghurt Science and Technology. 2nd ed. Woodhead, Cambridge, UK.

Tamura, K. J. Dudley, M. Nei, and S. Kumar. 2007. MEGA4: Molecular evolutionary genetics analysis (MEGA) software version 4.0 Mol. Biol. Evol. 24:1596-1599.

Wang, J., Z. Guo, Q. Zhang, L. Yan, W. Chen, X. Liu, and H. Zhang. 2009. Fermentation characteristics and transit tolerance of probiotic Lactobacillus casei Zhang in soymilk and bovine milk during storage. J. Dairy Sci. 92:2468-2476. 